\title{
Relaxing the Conductivity/Transparency Trade-Off in MOCVD ZnO Thin Films by Hydrogen Plasma
}

\author{
Laura Ding,* Sylvain Nicolay, Jérôme Steinhauser, Ulrich Kroll, and Christophe Ballif
}

Increasing the conductivity of polycrystalline zinc oxide films without impacting the transparency is a key aspect in the race to find affordable and high quality material as replacement of indium-containing oxides. Usually, $\mathrm{ZnO}$ film conductivity is provided by a high doping and electron concentration, detrimental to transparency, because of free carrier absorption. Here we show that hydrogen post-deposition plasma treatment applied to $\mathrm{ZnO}$ films prepared by metalorganic low-pressure chemical vapor deposition allows a relaxation of the constraints of the conductivity/transparency trade-off. Upon treatment, an increase in electron concentration and Hall mobility is observed. The mobility reaches high values of 58 and $46 \mathrm{~cm}^{2} \mathrm{~V}^{-1} \mathrm{~s}^{-1}$ for $2-\mu \mathrm{m}$ and 350-nm-thick films, respectively, without altering the visible range transparency. From a combination of opto-electronic measurements, hydrogen is found, in particular, to reduce electron trap density at grain boundaries. After treatment, the values for intragrain or optical mobility are found similar to Hall mobility, and therefore, electron conduction is found to be no longer limited by the phenomenon of grain boundary scattering. This allows to achieve mobilities close to $60 \mathrm{~cm}^{2} \mathrm{~V}^{-1} \mathrm{~s}^{-1}$, even in ultra-transparent films with carrier concentration as low as $10^{19} \mathrm{~cm}^{-3}$.

\section{Introduction}

Zinc oxide $(\mathrm{ZnO})$ has the advantage over other transparent conductive oxide (TCO) materials like indium oxide and tin oxide of being both very abundant and more chemically stable in reducing environments like hydrogen-rich plasmas. Yet, it is more difficult to make it as conductive as tin-doped indium oxide (ITO, resistivity typically $\leq 1 \times 10^{-4} \Omega \mathrm{cm}$ ), even by extrinsic doping with group III or group VII elements. ${ }^{[1,2]}$ For the particular application of electrodes for silicon-based (Si) solar cells, many research efforts have been focusing on maximizing the transparency of polycrystalline $\mathrm{ZnO}$ films. Increasing the transparency in the red/IR range can be readily achieved by reducing the impurity doping level:;[3] however, this is usually achieved at the expense of conductivity. Different

L. Ding, Dr. S. Nicolay, Prof. C. Ballif École Polytechnique Fédérale de Lausanne (EPFL) Institute of Microengineering (IMT)

Photovoltaics and Thin Film Electronics Laboratory rue A.-L. Breguet 2, CH-2000 Neuchâtel, Switzerland E-mail: laura.ding@epfl.ch

Dr. J. Steinhauser, Dr. U. Kroll

TEL Solar-Lab, rue du Puits-Godet 12A

$\mathrm{CH}-2000$ Neuchâtel, Switzerland solutions are now being developed with the aim of relaxing this conductivity/ transparency trade-off by increasing the charge carrier mobility. ${ }^{[4,5]}$

In this contribution, we discuss an approach based on hydrogen plasma post-deposition treatment $\left(\mathrm{H}_{2}\right.$ plasma $)$ to improve the electron mobility and the conductivity of $\mathrm{ZnO}$ films prepared by metalorganic chemical vapor deposition at low-pressure (LP-MOCVD). Indeed, Van de Walle determined that hydrogen is exclusively a shallow donor in $\mathrm{ZnO}$ and suggested that hydrogen is the main source of its native n-type conductivity. ${ }^{[6-8]}$ Many publications have since demonstrated the beneficial impact on conductivity of integrating hydrogen during growth, ${ }^{[9,10]}$ post-deposition treatment annealing in hydrogen, ${ }^{[11,12]}$ or hydrogen plasma exposure. ${ }^{[13-17]}$ Indeed, in addition to diffuse in bulk $\mathrm{ZnO}$ and to form shallow donors, ${ }^{[7,8,18-20]}$ hydrogen was reported to form complexes with native defect impurities acting as deep-level acceptor centers (like $\mathrm{Zn}$ vacancies, nitrogen or metal impurities), passivating them and hence resulting also in an increase in the free electron concentration and conductivity. ${ }^{[17,18]}$ In polycrystalline $\mathrm{ZnO}$ films, hydrogen is expected to interact similarly as in bulk $\mathrm{ZnO},{ }^{[9,10,14]}$ but moreover it can also passivate defects at grain boundaries. ${ }^{[12,13]}$ Typical defects at grain boundaries can be dangling bonds, intrinsic or dopant impurities segregating from the bulk in the grain boundaries, ${ }^{[21-23]}$ or chemisorbed oxygen species. ${ }^{[11,14,16,24,25]}$

Here, we focus on $\mathrm{H}_{2}$ plasma-induced reduction of the electron trap density at grain boundaries. We investigate changes in electron transport, IR reflectance and apply model equations for the mobility to determine the defect states density at grain boundary. We demonstrate that $\mathrm{H}_{2}$ plasma-treated layers combine outstanding transparency and conductivity, and report remarkable mobility values-increased from typically 20-30 to 60 for non-doped 2- $\mu \mathrm{m}$-thick films-for polycrystalline $\mathrm{ZnO}$ films, prepared with easily scalable methods and soft conditions..$^{[4,26,27]}$ Indeed, similar mobility values were reported in doped single crystal $\mathrm{ZnO}$ of equivalent electron concentration, ${ }^{[21]}$ or for high quality MOCVD ZnO film, ${ }^{[28]}$ but deposited at higher temperature $\left(380{ }^{\circ} \mathrm{C}\right.$, instead of $\left.165^{\circ} \mathrm{C}\right)$, and with very low electron concentration $\left(<10^{18} \mathrm{~cm}^{-3}\right)$, therefore with a conductivity one order of magnitude lower than the LP-MOCVD ZnO films presented in this contribution.

DOI: 10.1002/adfm.201203541 


\section{Results and Discussions}

Figure 1 shows the change in electrical properties of LPMOCVD ZnO films with different thicknesses and doping levels, in the as-deposited state and after $\mathrm{H}_{2}$ plasma. For the as-deposited layers (Figure 1a), we observe that a large range of resistivities and electron mobilities is obtained by varying both doping level and thickness. In polycrystalline conductive films like LP-MOCVD $\mathrm{ZnO}$, the Hall electron mobility $\left(\mu_{\text {Hall }}\right)$ depends on intragrain mobility $\left(\mu_{\text {intragrain }}\right)$ and grain boundaries mobility $\left(\mu_{\mathrm{GB}}\right)$. $^{[29-31]} \mu_{\text {intragrain }}$ is usually dominated by ionized impurity scattering at room-temperature (principally determined by the doping level), whereas $\mu_{\mathrm{GB}}$ is determined by the density of grain boundaries and the intensity of electron scattering at grain boundaries. ${ }^{[22,27,31,32]}$ The latter is controlled by the electron trap density $\left(N_{\mathrm{t}}\right)$ and the free electron concentration $\left(N_{\text {Hall }}\right)$. For all the samples in our series, we consider that the product of the grain size $(\approx 25-250 \mathrm{~nm})$ times the electron concentration $\left(9.8 \times 10^{18}-1.2 \times 10^{20} \mathrm{~cm}^{-3}\right)$ is larger than $N_{\mathrm{t}}\left(<3.0 \times 10^{13} \mathrm{~cm}^{-2}\right)$, so that the grains are not fully depleted of their carriers. Then the energetic potential barrier $\phi_{\mathrm{B}}$ at grain boundaries can be described, in first approximation, by: $:^{[21,22]}$

$\varphi_{\mathrm{B}}=\frac{q^{2} N_{\mathrm{t}}^{2}}{8 \varepsilon \varepsilon_{0} N_{\mathrm{Hall}}}$

where $\varepsilon \varepsilon_{0}$ is the static dielectric constant and $q$ is the elementary charge.

An increase in layer thickness leads to a higher mobility due to the formation of larger grains that reduce the grain boundaries density. ${ }^{[27,33,34]}$ An increase in the doping leads to an increase in the $N_{\text {Hall }}$ (Figure 1), and results in a decrease of energetic barrier, according to Equation 1. Overall, as expected,

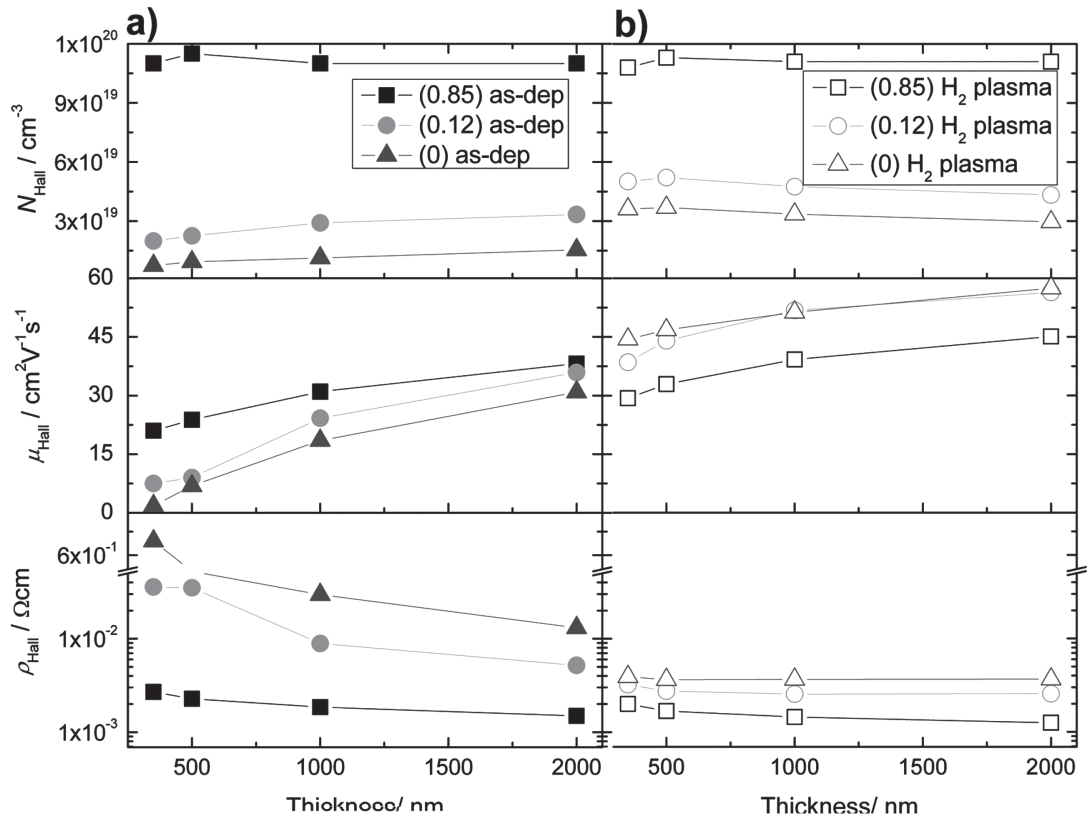

Figure 1. Electrical properties of a) as-deposited and b) $\mathrm{H}_{2}$ plasma treated $\mathrm{ZnO}$ films with different initial doping $\left(\mathrm{B}_{2} \mathrm{H}_{6} / D E Z\right.$ flows ratio indicated in parentheses) as a function of film thickness.

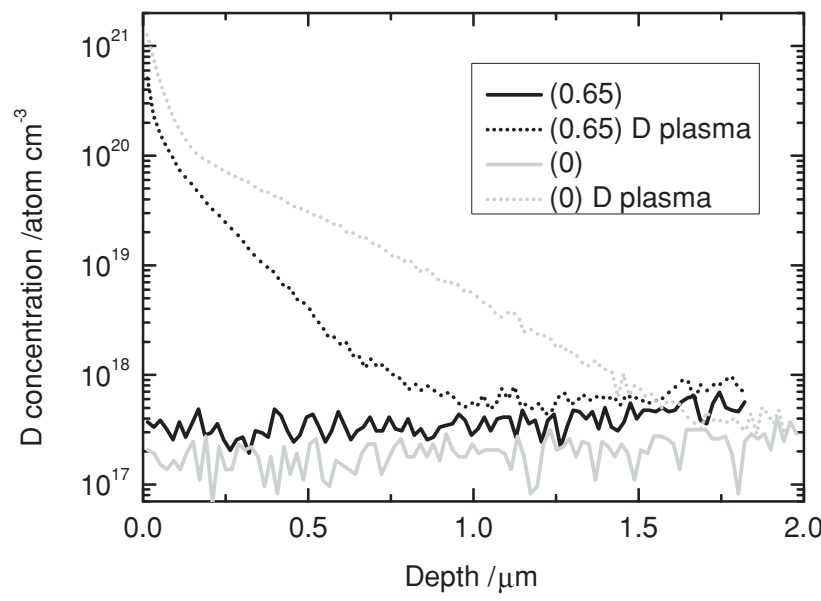

Figure 2. SIMS profile of deuterium in n-i-d and doped (0.65) $2-\mu \mathrm{m}$-thick $\mathrm{ZnO}$ films, before and after deuterium plasma treatment.

the resistivity $\left(\rho_{\text {Hall }}\right)$ of as-deposited layers decreases both with increasing thickness and doping.

After $\mathrm{H}_{2}$ plasma, a strong decrease in $\rho_{\text {Hall }}$ is measured for all layers, associated with a large increase in electron mobility, as well as a moderate increase in electron concentration of approximately $1.5 \times 10^{19} \mathrm{~cm}^{-3}$ (Figure $1 \mathrm{~b}$ ). The mobility has more than doubled after $\mathrm{H}_{2}$ plasma for $2-\mu \mathrm{m}$-thick non-intentionally doped (i.e., $\mathrm{B}_{2} \mathrm{H}_{6} / \mathrm{DEZ}$ flows ratio of 0 , n-i-d) $\mathrm{ZnO}$ film, and even multiplied by ten for the n-i-d 350-nm-thick $\mathrm{ZnO}$ film. These layers reach remarkably high mobility values of $58 \mathrm{~cm}^{2} \mathrm{~V}^{-1} \mathrm{~s}^{-1}$ and $46 \mathrm{~cm}^{2} \mathrm{~V}^{-1} \mathrm{~s}^{-1}$, respectively. Hydrogen can easily diffuse in $\mathrm{ZnO}$ single crystals during plasma exposure; ${ }^{[19]}$ in addition, grain boundaries in polycrystalline $\mathrm{ZnO}$ provide fast diffusion paths (in and out). ${ }^{[15,20]}$ To investigate the diffusion of hydrogen in LP-MOCVD ZnO during plasma exposure, we performed secondary ion mass spectroscopy (SIMS) analysis on deuterium (D) plasma treated films. Deuterium, instead of hydrogen, was used for SIMS to distinguish species introduced by the plasma exposure from hydrogen natively present in the films. Prior to analysis, we measured the electrical properties of deuterium plasma-treated films, and their electron concentration and mobility were equal to the values after $\mathrm{H}_{2}$ plasma. Figure 2 shows the depth profile concentration of deuterium in n-i-d and doped $\left(\mathrm{B}_{2} \mathrm{H}_{6}\right)$ DEZ flows ratio of 0.65 ) films, before and after treatment. Both films contain deuterium, showing that hydrogen can interact deeply in the bulk of the $\mathrm{ZnO}$. Higher concentrations of deuterium are measured near the surface. The concentration decays over the first micrometer for the doped film, to reach a constant value higher than before treatment, whereas the concentration profile of the $n$-i-d film decays linearly over the total $2 \mu \mathrm{m}$ thickness. This might be linked to a 
difference in their microstructure, ${ }^{[20]}$ but will not be discussed further here. Hydrogen has been reported to act as dopant, but also to passivate acceptor-defects: all resulting in an increase in free carrier concentration. ${ }^{[14,16]}$ Therefore, we suggest that the increase in $N_{\text {Hall }}$ can be attributed to similar effects, including the release of some free carriers from passivated traps. This is further supported by the observation of a slight but systematic more pronounced increase in $\mathrm{N}_{\mathrm{Hall}}$ after $\mathrm{H}_{2}$ plasma for the thinnest layers, where the density of grain boundaries-and hence trapped-electron density-are the highest. It is important to note here that the observed increase in $\mu_{\mathrm{Hall}}$ cannot be explained by the increase in $N_{\text {Hall }}$ only. As can be seen in Figure 1, while the electron density is similar for n-i-d $\mathrm{H}_{2}$ plasma-treated and as-deposited doped (0.12) $\mathrm{ZnO}$ layers, the mobility of the latter is lower. The Hall mobility is influenced by the barrier potential at grain boundaries, so according to Equation 1, if for same $N_{\text {Hall }}, \mu_{\text {Hall }}$ is higher, the trap density at grain boundary $N_{\mathrm{t}}$ must be lower. Also, the largest $\mu_{\text {Hall }}$ gains (a factor of 10) occur for the thinnest, least doped samples that are initially characterized by the lowest mobility (due to high grain density and high grain boundary potential barriers). However, after treatment, these samples exhibit higher mobility than the highly doped films. In addition, a decrease in grain boundary density can be ruled out as the cause of the mobility gain, as $\mathrm{H}_{2}$ plasma was reported not to induce any structural crystallographic rearrangement. ${ }^{[16]}$ Therefore, we conclude that, after $\mathrm{H}_{2}$ plasma, the increase in $\mu_{\text {Hall }}$ is due mainly to grain boundary defect density reduction.

To evaluate the decrease in electron trap density by $\mathrm{H}_{2}$ plasma, we calculated $N_{\mathrm{t}}$ in as-deposited and $\mathrm{H}_{2}$ plasma-treated layers from $\mu_{\text {Hall }}, N_{\text {Hall }}$ and the grain size $(L)$ (evaluated from scanning electron microscopy images). Indeed, as discussed before, both intragrain and grain boundary mobility contribute to $\mu_{\mathrm{Hall}}$. In LP-MOCVD ZnO films, $\mu_{\text {intragrain }}$ can be described in first approximation by the semi-empirical fit formula developed by Masetti et al. for doped Si single crystals and adapted for crystalline $\mathrm{ZnO}$ by Ellmer: ${ }^{[32,35}$

$\mu_{\text {Masetti }}=\mu_{\min }+\frac{\mu_{\max }-\mu_{\min }}{1+\left(N_{\text {Hall }} / N_{\text {ref1 }}\right)^{\alpha_{1}}}-\frac{\mu_{1}}{1+\left(N_{\text {ref2 }} / N_{\text {Hall }}\right)^{\alpha_{2}}}$

where $\mu_{\min }$ is the ionized impurity mobility at high electron concentrations, $\mu_{\max }$ is the lattice mobility at low electron concentrations, and $\left(\mu_{\max }-\mu_{1}\right)$ is the clustering mobility at very high electron concentrations. ${ }^{[35]}$

Furthermore, $\mu_{\mathrm{GB}}$ can be expressed as a combination of the thermionic emission mobility $\left(\mu_{\mathrm{th}}\right)$ and the tunneling mobility $\left(\mu_{\text {tun }}\right)_{:[22,36]}$ $\mu_{\mathrm{th}}=\frac{q \mathrm{~W}}{\sqrt{2 \pi m^{*} k T}} \exp \left(\frac{-\varphi_{\mathrm{B}}}{k T}\right)$

$\mu_{\text {tun }}=\frac{q l_{\text {tun }}}{\hbar\left(3 \pi^{2} N_{\text {Hall }}\right)^{1 / 3}} \exp \left(\frac{-4 \pi \mathrm{W} \sqrt{2 m^{*} \varphi_{\mathrm{B}}}}{h}\right)$

where $W$ is the ratio $N_{\mathrm{t}} / N_{\text {Hall }}$ representing the width of the depletion zone at grain boundaries, $m^{*}$ is the electron effective mass $\left(0.28\right.$ of the electron mass $\left(m_{\mathrm{e}}\right)$ for doped $\mathrm{ZnO}$ and $0.2 m_{\mathrm{e}}$ for lowly doped $\mathrm{ZnO}$ ), ${ }^{[37]} \mathrm{T}$ is the temperature, $\phi_{\mathrm{B}}$ is the potential barrier height given by Equation $1, k$ and $h$ are the Boltzmann and Planck constants, respectively, $\hbar$ is $h / 2 \pi$ and $l_{\text {tun }}$ is the electron tunneling length, fixed at $5 \mathrm{~nm} \cdot{ }^{[36]}$

Finally, the one-dimensional Hall effective mobility is given by: ${ }^{[36]}$

$\frac{1}{\mu_{\text {Hall }}}=\frac{L-W}{L}\left(\frac{1}{\mu_{\text {Masetti }}}\right)+\frac{W}{L}\left(\frac{1}{\mu_{\text {th }}+\mu_{\text {tun }}}\right)$

Table 1 summarizes the parameters used for calculations and the $N_{\mathrm{t}}$ values obtained for 2- $\mu$ m-thick films with $\mathrm{B}_{2} \mathrm{H}_{6} / \mathrm{DEZ}$ flows ratio between 0 and 0.85 . The films prepared with the highest doping exhibit the highest $N_{\mathrm{t}}$ values, before and after treatment. In fact, B-doping by introducing diborane during deposition has been shown to induce the growth of a more defective material, ${ }^{[38]}$ with reduced grain size and therefore increased grain boundary density and $N_{\mathrm{t}} \cdot{ }^{\left[{ }^{33]}\right.}$ It seems here that incorporated B atoms not only induce defects in the bulk, but also in the grain boundary material. After $\mathrm{H}_{2}$ plasma, the $N_{\mathrm{t}}$ reduction is the largest for the most doped samples too, which might indicate a passivation process involving B-related defects. Indeed, if we compare again the $2-\mu \mathrm{m}$-thick doped $(0.12)$ and n-i-d $\mathrm{H}_{2}$ plasma-treated layers, the n-i-d $\mathrm{H}_{2}$ plasma-treated layer shows a lower $N_{\mathrm{t}}$, despite same $N_{\text {Hall }}$. It seems that post-deposition $\mathrm{H}$-doping, in contrast to B-doping during growth, does not cause the creation of defects at grain boundaries. These results seem to indicate that the mobility of the doped samples improves rather due to a passivation of defects at grain boundaries than due to the increase in $N_{\text {Hall }}$, whereas the mobility of the n-i-d would improve due to the increase in $N_{\text {Hall }}$ and related decrease of potential barrier, rather than due to the slight reduction in $N_{\mathrm{t}}$.

Complementary experiments were performed to discriminate which from the annealing under vacuum, exposure to ultraviolet (UV) light, or complete plasma exposure, is the dominant contribution that improves mobility. $2-\mu \mathrm{m}$-thick $n$-i-d $\mathrm{ZnO}$ samples were exposed to (i) vacuum annealing in the same reactor at $200{ }^{\circ} \mathrm{C}$ for $40 \mathrm{~min}$, (ii) $\mathrm{H}_{2}$ plasma with a

Table 1. Summary of the calculated grain boundary defect density $\left(N_{t}\right)$ of 2- $\mu \mathrm{m}$-thick $\mathrm{ZnO}$ samples with various doping level, before and after $\mathrm{H}_{2}$ plasma treatment. Electron concentration $\left(N_{\text {Hall }}\right)$ and mobility $\left(\mu_{\text {Hall }}\right)$ values used for the calculation are also shown.

\begin{tabular}{|c|c|c|c|c|c|c|c|}
\hline \multirow[b]{2}{*}{$\mathrm{B}_{2} \mathrm{H}_{6} / \mathrm{DEZ}$} & \multirow[b]{2}{*}{$L[\mathrm{~nm}]$} & \multicolumn{2}{|c|}{$N_{\text {Hall }}\left[10^{19} \mathrm{~cm}^{-3}\right]$} & \multicolumn{2}{|c|}{$\mu_{\text {Hall }}\left[\mathrm{cm}^{2} \mathrm{~V}^{-1} \mathrm{~s}^{-1}\right]$} & \multicolumn{2}{|c|}{$N_{\mathrm{t}}\left[10^{12} \mathrm{~cm}^{-2}\right]$} \\
\hline & & As-dep & $\mathrm{H}_{2}$ plasma & As-dep & $\mathrm{H}_{2}$ plasma & As-dep & $\mathrm{H}_{2}$ plasma \\
\hline 0.85 & 200 & 11 & 12 & 38 & 45 & 28 & 20 \\
\hline 0.3 & 220 & 5.8 & 6.5 & 39 & 53 & 15 & 11 \\
\hline 0.12 & 250 & 3.3 & 4.5 & 34 & 56 & 12 & 7 \\
\hline 0 & 280 & 1.3 & 3 & 26 & 58 & 8 & 7 \\
\hline
\end{tabular}


Table 2. Electrical properties of $2-\mu m$-thick $n$-i-d $\mathrm{ZnO}$ films exposed to various treatments.

\begin{tabular}{lccc}
\hline Treatment & $N_{\text {Hall }}\left[10^{19} \mathrm{~cm}^{-3}\right]$ & $\mu_{\text {Hall }}\left[\mathrm{cm}^{2} \mathrm{~V}^{-1} \mathrm{~s}^{-1}\right]$ & $\rho_{\text {Hall }}\left[10^{-2} \Omega \mathrm{cm}\right]$ \\
\hline None & 1.2 & 23 & 2.25 \\
Annealing & 1.4 & 25 & 1.75 \\
UV- annealing & 1.5 & 37 & 1.2 \\
$\mathrm{H}_{2}$ plasma & 2.3 & 58 & 0.45 \\
\hline
\end{tabular}

$0.5 \mathrm{~mm}$ AF45 glass covering the $\mathrm{ZnO}$ surface to prevent surface-interactions with species in the plasma, but still allow annealing and some UV light transmission, and (iii) complete $\mathrm{H}_{2}$ plasma. Table 2 presents the electrical properties of the $2-\mu \mathrm{m}$-thick n-i-d $\mathrm{ZnO}$ films, before and after the various treatments. Both annealing and UV-annealing treatments lead to a reduction in resistivity. The UV-exposed sample has a higher $\mu_{\text {Hall }}$ than the vacuum-annealed-only sample, which is attributed to photoconductivity that enhances desorption of oxygen species acting as electron traps at grain boundaries. ${ }^{[24,39]}$ Finally, the complete plasma exposure leads to the largest improvement in both $N_{\text {Hall }}$ and $\mu_{\text {Hall }}$, which means that species in the plasma, interacting with the $\mathrm{ZnO}$, play a crucial role. Further investigations are now required to determine the nature of the passivated defects that might include oxygen species. ${ }^{[11,24,25]}$

Continuing with the mobility analysis, we evaluated the intragrain mobility of $\mathrm{ZnO}$ layers, using the Drude model to fit IR reflectance spectra. ${ }^{[31]}$ Figure 3 shows $\mu_{\text {intragrain }}$ for n-i-d $\mathrm{ZnO}$ films as a function of the layer thickness, together with $\mu_{\text {Hall }}$ from Figure 1. After $\mathrm{H}_{2}$ plasma, $\mu_{\text {Hall }}$ reaches values as high as $\mu_{\text {intragrain. }}$ This demonstrates that the Hall effective mobility is no longer governed by grain boundary scattering after $\mathrm{H}_{2}$ plasma, and is limited only by intragrain scattering, according to Equation 5. Remarkably, the mobility of the 2- $\mu$ m-thick n-i-d $\mathrm{H}_{2}$ plasma treated film reaches values close to $60 \mathrm{~cm}^{2} \mathrm{~V}^{-1} \mathrm{~s}^{-1}$, measured for doped $\mathrm{ZnO}$ single crystals with the same electron concentration $\left(3 \times 10^{19} \mathrm{~cm}^{-3}\right)^{[21,35]}$ and matches the mobility calculated for intragrain scattering using the adapted formula fit from Masetti et al. and Ellmer. ${ }^{[32,35]}$

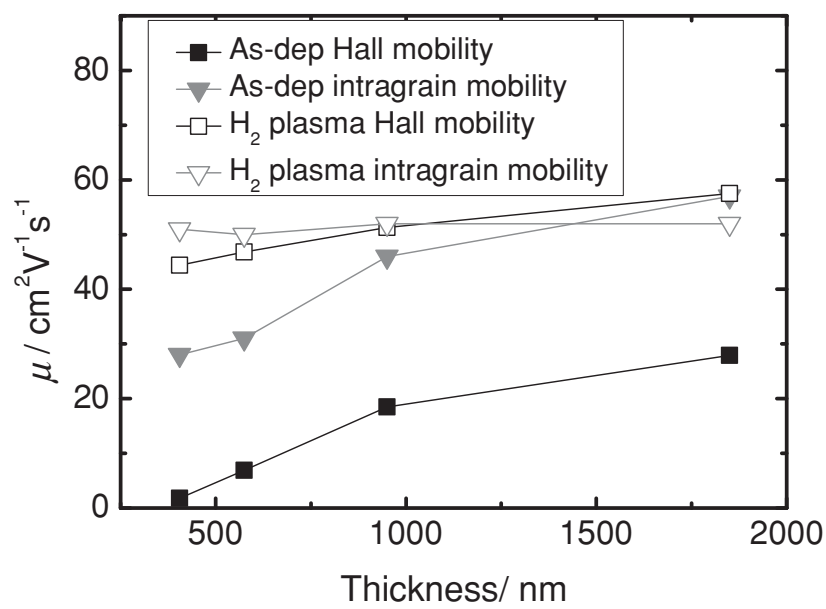

Figure 3. Hall effect electron mobility and intragrain mobility for 2- $\mu \mathrm{m}$ thick $\mathrm{n}$-i-d $\mathrm{ZnO}$ films before and after $\mathrm{H} 2$ plasma treatment.
We next performed T-dependent Hall effect measurements on n-i-d and (0.65) doped films to investigate changes in electron transport due to $\mathrm{H}_{2}$ plasma. As $N_{\text {Hall }}$ is constant for all $\mathrm{T}$ (Figure 4a), conductivity variations are ascribed to mobility variations only (Figure $4 b$ ). In Figure 4c, the conductivity of the asdeposited (0.65) layer decreases at high $T$. Indeed, the conductivity of doped $\mathrm{ZnO}$ is dominated by T-independent ionized impurity scattering and tunneling (field emission) transport through the narrow grain boundary potential barrier, combined with thermally activated phonon scattering, which causes the conductivity to drop, as $T$ is increased ${ }^{[36,40]}$ Conversely, the conductivity of the as-deposited n-i-d layer is almost constant, and slightly increases for high $T$, which is typical for thermally activated thermionic emission transport over the high grain boundary potential barrier. ${ }^{[22,24,36]}$ As discussed before, we proposed that $\mathrm{H}_{2}$ plasma modifies the potential barrier by defect passivation and doping, and therefore it should also result in a change in $T$-dependent conductivity. Indeed, the conductivity of n-i-d $\mathrm{H}_{2}$ plasma-treated films also decreases for high $T$, like the doped films. This means that the potential barriers of passivated grain boundaries are narrow enough to enable tunneling transport, and also that ionized impurity scattering is the dominant scattering mechanism at room-temperature, though $N_{\text {Hall }}$ is almost one order of magnitude lower for n-i-d $\mathrm{H}_{2}$ plasma-treated films than for doped layers. Finally, we observe that the conductivity of the $(0.65)$ doped film follows the same thermally restricted trend before and after $\mathrm{H}_{2}$ plasma, though more accentuated.

$\mathrm{ZnO}$ films prepared by radio frequency magnetron sputtering and annealed under a $\mathrm{Si}$ cap at high temperature were recently reported to exhibit $\mu_{\text {Hall }}$ values as high as $67 \mathrm{~cm}^{2} \mathrm{~V}^{-1} \mathrm{~s}^{-1}$, for $N_{\text {Hall }}$ around $5 \times 10^{20} \mathrm{~cm}^{-3} \cdot{ }^{[41,42]}$ The authors ascribed the remarkable improvement in $\mu_{\text {Hall }}$ to grain boundary defect passivation, as well as to a decrease in various possible intragrain scattering factors. In our study, however, such high temperature $\left(600^{\circ} \mathrm{C}\right)$ was not reached, so that passivation of crystallographic defects is unlikely to have occurred. These possible remaining sources of intragrain scattering could explain why $\mathrm{H}_{2}$ plasmatreated $\mathrm{ZnO}$ films do not reach mobility values above $60 \mathrm{~cm}^{2}$ $\mathrm{V}^{-1} \mathrm{~s}^{-1}$. Still, the values are close, and $\mathrm{H}_{2}$ plasma treatment has the advantage of being more straightforward, as it does not require the post-deposition of additional layers.

Regarding the film optical properties, the absorptance spectra of n-i-d and (0.65) layers are slightly modified after $\mathrm{H}_{2}$ plasma (Figure 5). We ascribe the modification to the increase in the free electron concentration, which results in band-gap widening (Burstein-Moss effect) in the UV range, ${ }^{[43]}$ and in an increase in free-carrier absorption in the red/IR part of the spectrum. ${ }^{[3]}$ Nevertheless, the $\mathrm{H}_{2}$ plasma-treated n-i-d layer still exhibits a very high transparency, with only $2 \%$ of absorptance in the visible range, and a slow increase in the infrared with only $3 \%$ absorptance at $1500 \mathrm{~nm}$. The combination of enhanced conductivity and high transparency in the spectral range of $\mathrm{Si}$ absorption $(370-1200 \mathrm{~nm})$ makes $\mathrm{H}_{2}$ plasma-treated LP-MOCVD $\mathrm{ZnO}$, and particularly the $\mathrm{n}$-i-d layers, excellent candidates for electrodes in optoelectronics application such as photovoltaic devices, light emitting diodes and or other TCO applications.

Finally, Figure 6 shows the IR reflectance spectra of a (0.3) doped $\mathrm{ZnO}$ film before and after $\mathrm{H}_{2}$ plasma. The intense reflectance at wavenumbers below $590 \mathrm{~cm}^{-1}$ is related to the 


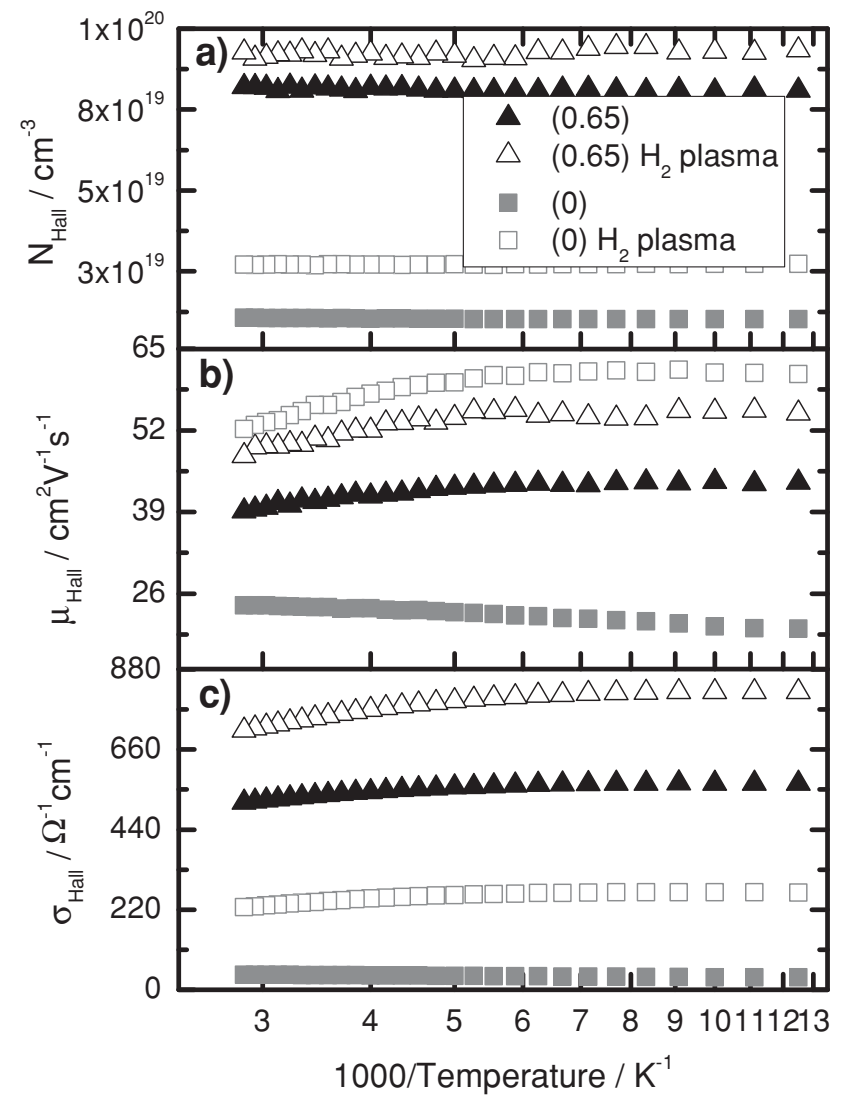

Figure 4. a) Electron concentration, b) mobility and c) conductivity as a function of inverse temperature of $n$-i-d and doped (0.65) 2- $\mu$ m-thick $\mathrm{ZnO}$ films, before and after $\mathrm{H}_{2}$ plasma treatment.

reststrahlen band of $\mathrm{ZnO} .{ }^{[44]}$ We observe a shift of the reflectance curve toward higher wavenumbers after $\mathrm{H}_{2}$ plasma, confirming an increase in the free carrier density, according to the Drude model. We also observe the disappearance of a peak located at approximately $590 \mathrm{~cm}^{-1}$. Recent Raman studies assigned a $583 \mathrm{~cm}^{-1}$ Raman band to defect structures, the

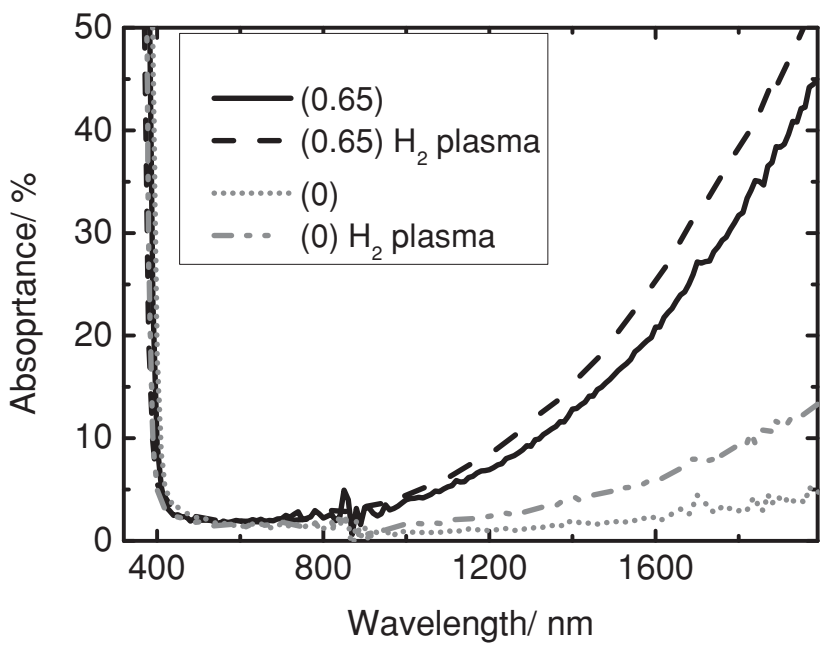

Figure 5. Absorptance spectra of of $n$-i-d and doped (0.65) 2- $\mu$ m-thick $\mathrm{ZnO}$ films, before and after $\mathrm{H}_{2}$ plasma treatment.

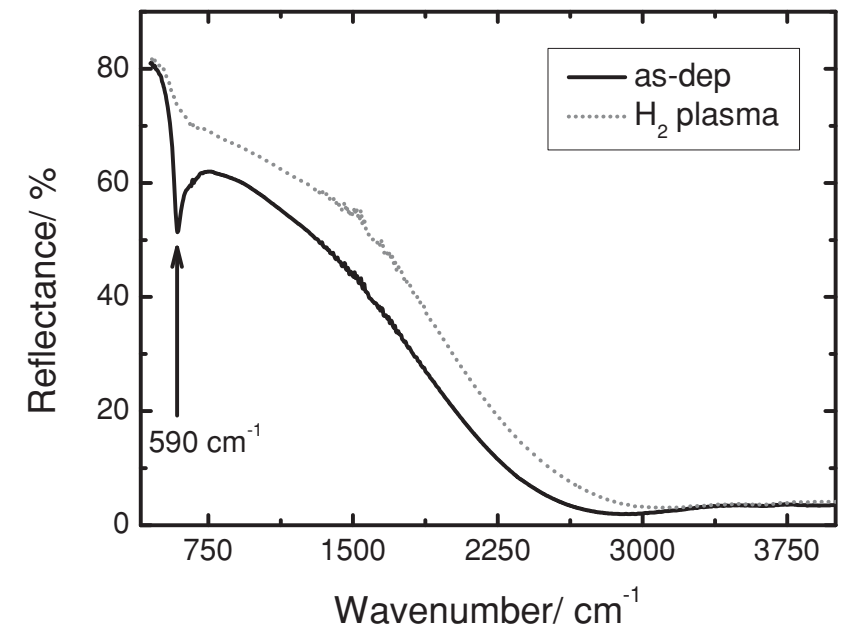

Figure 6. Infrared reflectance spectra of a doped (0.3) 2- $\mu \mathrm{m}$-thick $\mathrm{ZnO}$ film before and after $\mathrm{H}_{2}$ plasma treatment.

intensity of which changes in response to $\mathrm{H}_{2}$ exposure. ${ }^{[45]}$ In this contribution, we hypothesize that these defect structures are linked to defect states in the material, including grain boundaries, and that the change in intensity of the $590 \mathrm{~cm}^{-1}$ peak can be seen as the signature of the defective or "cured" material.

\section{Conclusions}

In summary, $\mathrm{H}_{2}$ plasma post-deposition treatment of LPMOCVD ZnO films led to a large increase in the mobility and conductivity with only a moderate increase in electron concentration. By using model equations for the electron mobility, the trap density at grain boundaries could be quantitatively evaluated. From these results, we postulate that boron doping by introducing diborane during $\mathrm{ZnO}$ growth causes the creation of defects, not only in the bulk material, but also at grain boundaries, which increases the electron trap density. In contrast, $\mathrm{H}_{2}$ plasma post-deposition treatment seems not to increase the initial trap density at grain boundaries. In fact, $\mathrm{H}_{2}$ plasma postdeposition treatment is proposed to improve the mobility due to combined effect of electron traps passivation and increase in electron concentration. Similar values of intragrain and Hall mobilities, together with the change in electron transport mechanism after $\mathrm{H}_{2}$ plasma, confirmed that the potential barrier at grain boundaries is reduced to a point where grain boundary scattering can be considered negligible, even for very low initial doping level. Finally, $\mathrm{H}_{2}$ plasma was shown to improve significantly the conductivity of $\mathrm{ZnO}$ films without altering their transparency in the visible range, ranking these films among the most transparent and conductive oxides reported so far. As a consequence, they open new perspectives for minimizing parasitic light-absorption in the electrodes of solar cells, a crucial step toward higher current and efficiency. More generally, $\mathrm{H}_{2}$ plasma appears to be an attractive post-deposition treatment for $\mathrm{ZnO}$ in all TCO applications, from heating windows to transparent electronics and detectors. 


\section{Experimental Section}

ZnO films were prepared by LP-MOCVD on Schott AF45 glass from diethylzinc $\left(\mathrm{Zn}\left(\mathrm{C}_{2} \mathrm{H}_{5}\right)_{2}, \mathrm{DEZ}\right)$ and water $\left(\mathrm{H}_{2} \mathrm{O}\right)$ vapor, and diborane $\left(\mathrm{B}_{2} \mathrm{H}_{6}\right)$ diluted in $\mathrm{Ar}$ at $1 \%$ as a boron dopant. ${ }^{[4,27]}$ The extrinsic doping level is controlled by the $\mathrm{B}_{2} \mathrm{H}_{6} / D E Z$ flow ratio, with the $\mathrm{H}_{2} \mathrm{O}$ and DEZ flows kept constant. Prior plasma treatment, samples were preheated for $20 \mathrm{~min}$, in vacuum $\left(2 \times 10^{-6} \mathrm{mbar}\right)$ at $200^{\circ} \mathrm{C}$. Hydrogen plasma post-deposition treatments were performed in a medium-sized plasmaenhanced chemical vapor deposition (PECVD) industrial KAI reactor. The hydrogen plasma was operated with a pressure of $0.5 \mathrm{mbar}$, power density of $0.15 \mathrm{~W} \mathrm{~cm}^{-2}$, excitation frequency of $40.68 \mathrm{MHz}$ and duration of $20 \mathrm{~min}$. The maximum energy of ions incident on the grounded electrode in the hydrogen plasma was calculated from the plasmapotential to be $65 \mathrm{eV}^{[46]}$ significantly lower than common values used for implantation of impurities, in the order of $100 \mathrm{keV}{ }^{[19]}$ The deuterium plasma post-deposition treatments were performed in a lab-scale size cluster PECVD system, and the deuterium plasma was operated at $0.5 \mathrm{mbar}, 0.15 \mathrm{~W} \mathrm{~cm}^{-2}, 54.24 \mathrm{MHz}$ and for $20 \mathrm{~min}$.

The films were electrically characterized by room-temperature and T-dependent $(80-350 \mathrm{~K})$ Hall effect measurements, using the Van der Pauw configuration. The Hall parameters were extracted assuming, for simplification, homogeneous layers in thickness. Elemental depth profiles for deuterium were obtained by SIMS analysis (performed by Evans Analytical Group LLC), having a reference deuterium implanted $\mathrm{ZnO}$ sample for quantification. Reflectance spectra were recorded between 400 and $4000 \mathrm{~cm}^{-1}$ with a Fourier transform IR spectrometer. The spectra were fitted with a Drude model to extract the intragrain mobility, using a three-layer stack consisting of a glass substrate, a bulk $\mathrm{ZnO}$ film, and an effective medium layer with variable volume concentrations of air and $\mathrm{ZnO}$, to take into account surface roughness. Absorptance spectra were obtained from transmittance and reflectance curves in the 320-2000 nm range using a dual-beam spectrophotometer with an integrating sphere. Diiodomethane was used as index matching to eliminate surface roughness effects during optical measurements.

\section{Acknowledgements}

The authors would like to thank Dr. M. Boccard, G. Bugnon and Dr. M. Despeisse for helpful discussions. We thank J. Seif for his help and time doing the deuterium plasma treatments. Finally, we gratefully acknowledge for fruitful discussions Dr. W. Beyer and Dr. J. Hüpkes from IEK-5 Forschungszentrum Jülich $\mathrm{GmbH}$. This work was supported by the Swiss Federal Office of Energy (OFEN) (grant No. 101191) and by the EU FP7 “N2p" project (Grant No CP-IP 214134-2 N2P).

Received: November 30, 2012 Revised: March 8, 2013

Published online: May 2, 2013

[1] T. Minami, MRS Bull. 2000, 25, 38 .

[2] T. Minami, Semicond. Sci. Technol. 2005, 20, S35.

[3] K. L. Chopra, S. Major, D. K. Pandya, Thin Solid Films 1983 102, 1.

[4] L. Ding, M. Boccard, G. Bugnon, M. Benkhaira, S. Nicolay, M. Despeisse, F. Meillaud, C. Ballif, Sol. Energy Mater. Sol. Cells $201298,331$.

[5] L. Ding, M. Boccard, G. Bugnon, M. Benkhaira, M. Despeisse, F. Sculati-Meillaud, S. Nicolay, P. A. Losio, O. Kluth, P. Carroy, O. Caglar, C. Ballif, IEEE J. Photovolt. 2012 2, 88.

[6] C. G. Van de Walle, Phys. Rev. Lett. 2000, 85, 1012

[7] A. Janotti, C. G. Van De Walle, Rep. Prog. Phys. 2009, 72, 126501.

[8] A. Janotti, C. G. Van de Walle, Nat. Mater. 2007, 6, 44.

[9] S. Y. Myong, K. S. Lim, Sol. Energy Mater. Sol. Cells 2005, 86, 105.
[10] S.Y. Myong, K.S. Lim, Org. Electron. 2007, 8, 51

[11] B. Y. Oh, M.-C. Jeong, J.-M. Myoung, Appl. Surf. Sci. 2007, 253, 7157.

[12] F. Chang, W. C. Lin, M. H. Hon, Appl. Surf. Sci. 2001, 183, 18.

[13] J. J. Dong, X. W. Zhang, J. B. You, P. F. Cai, Z. G. Yin, Q. An, X. B. Ma, P. Jin, Z. G. Wang, P. K. Chu, ACS Appl. Mater. Interfaces 2010, 2, 1780.

[14] P. F. Cai, J. B. You, X. W. Zhang, J. J. Dong, X. L. Yang, Z. G. Yin, N. F. Chen, J. Appl. Phys. 2009, 105, 083713.

[15] C. A. Wolden, T. M. Barnes, J. B. Baxer, E. S. Aydil, J. Appl. Phys. 2005, 97, 043522.

[16] H.P. Chang, F.H. Wang, J.Y. Wu, C.Y. Kung, H.W. Liu, Thin Solid Films 2010, 518, 7445.

[17] B. Theys, V. Sallet, F. Jomard, A. Lusson, J.-F. Rommeluère, Z. Teukam, J. Appl. Phys. 2002, 91, 3922.

[18] M. D. Mc Cluskey, S. J. Jokela, J. Appl. Phys. 2009, 106, 071101.

[19] K. Ip, M. E. Overberg, Y. W. Heo, D. P. Norton, S. J. Pearton, Appl. Phys. Lett. 2003, 82, 385.

[20] W. Beyer, F. Hamelmann, D. Knipp, D. Lennartz, P. Prunici, A. Raykov, H. Stiebig, in Proc. 25th EU PVSEC, Valencia, Spain 2010, 3094.

[21] K. Ellmer, A. Klein, B. Rech, Transparent Conductive Zinc Oxide, Springer, Berlin-Heidelberg 2008, 104.

[22] J. Y. W. Seto, J. Appl. Phys. 1975, 46, 5247.

[23] C. R. M. Grovenor, J. Phys. C: Solid State Phys. 1985, 18, 4079

[24] A. P. Roth, D. F. Williams, J. Appl. Phys. 1981, 52, 6685.

[25] T. Minami, H. Nanto, S. Shooji, S. Takata, Thin Solid Films 1984, $111,167$.

[26] W. W. Wenas, A. Yamada, K. Takahashi, M. Yoshino, M. Konagai, J. Appl. Phys. 1991, 70, 7119.

[27] S. Faÿ, J. Steinhauser, S. Nicolay, C. Ballif, Thin Solid Films 2010, $518,2961$.

[28] K. T. Roro, G. H. Kassier, J. K. Dangbegnon, S. Sivaraya, J. E. Westraadt, J. H. Neethling, A. W. R. Leitch, J. R. Botha, Semicond. Sci. Technol. 2008, 23, 055021.

[29] J. W. Orton, M. J. Powell, Rep. Prog. Phys. 1980, 43, 1263.

[30] J. Steinhauser, S. Faÿ, N. Oliveira, E. Vallat-Sauvain, D. Zimin, U. Kroll, C. Ballif, Phys. Status Solidi A 2008, 205, 1983.

[31] J. Steinhauser, S. Faÿ, N. Oliveira, E. Vallat-Sauvain, C. Ballif, Appl. Phys. Lett. 2007, 90, 142107.

[32] G. Masetti, M. Severy, S. Solmi, IEEE Trans. Electron Devices 1983, 30, 764 .

[33] S. Faÿ, L. Feitknecht, R. Schluchter, U. Kroll, E. Vallat-Sauvain, A. Shah, Sol. Energy Mater. Sol. Cells 2006, 90, 2960.

[34] S. Nicolay, S. Faÿ, C. Ballif, Cryst. Growth Des. 2009, 9, 4957.

[35] K. Ellmer, J. Phys. D: Appl. Phys. 2001, 34, 3097.

[36] J. Steinhauser, Ph. D. thesis, University of Neuchâtel, Switzerland 2008.

[37] F. Ruske, A. Pflug, V. Sittinger, B. Szyszka, D. Greiner, B. Rech, Thin Solid Films 2009, 518, 1289

[38] M. L. Addonizio, C. Diletto, Sol. Energy Mater. Sol. Cells 2008, 92, 1488.

[39] D. H. Zhang, Mater. Chem. Phys. 1996, 45, 248.

[40] Y. Myong, J. Steinhauser, R. Schlüchter, S. Faÿ, E. Vallat-Sauvain, A. Shah, C. Ballif, A. Rüfenacht, Sol. Energy Mater. Sol. Cells 2007, 91, 1269.

[41] K. Y. Lee, C. Becker, M. Muske, F. Ruske, S. Gall, B. Rech, M. Berginski, J. Hüpkes, Appl. Phys. Lett. 2007, 91, 241911.

[42] F. Ruske, M. Roczen, K. Lee, M. Wimmer, S. Gall, J. Hüpkes, D. Hrunski, B. Rech, J. Appl. Phys. 2010, 107, 013708.

[43] a) E. Burstein, Phys. Rev. 1954, 93, 632; b) T. S. Moss, Proc. Phys. Soc. London Ser. B 1954, 67, 775

[44] R. J. Collins, D. A. Kleinman, J. Phys. Chem. Solids 1959, 11, 190.

[45] C. F. Windisch, G. J. Exarhos, C. Yao, L.-Q. Wang, J. Appl. Phys. 2007, 101, 123711.

[46] K. Köhler, D. E. Horne, J. W. Coburn, J. Appl. Phys 1985. 58, 3350. 